\title{
Risky manager
}

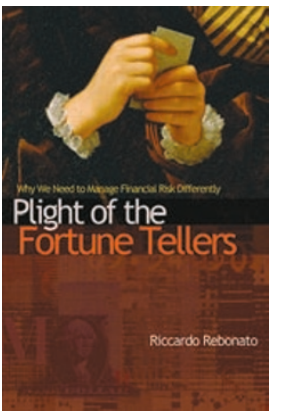

\section{PLIGHT OF THE FORTUNE TELLERS: WHY WE NEED TO MANAGE FINANCIAL RISK DIFFERENTLY BY RICCARDO REBONATO}

Princeton Univ. Press: 2007. 272 pp. \$35
I must admit that I was reluctant to review this book when first approached. We in financial risk management were, and remain, very busy given the current conditions of the markets, the 'subprime' concerns and the fast approaching deadlines related to the Basle II implementation. For those not acquainted with the banking industry, Basle II refers to a new set of capital rules that banks need to implement and follow. In any case, reading another book on risk management did not strike me as a pleasant distraction from my day-to-day activities. Nonetheless, I decided to browse through the book and quickly realized this was not like any other book on risk management.

What immediately caught my eye was that there were no equations and some very interesting chapter titles such as 'Thinking about Risk', 'What is Risk Management For?' and 'The Promise of Economic Capital'. All of these concepts are at the heart of modern risk management and are daily topics of discussion at the workplace. I wanted to know Riccardo Rebonato's opinion on these subjects.

The main thrust of the book is that the current state of financial risk management is at a crossroads. Rebonato argues that there is an inconsistency between the expectations of regulators, senior-level managers and what is actually achievable given the limitations of market data and modelling. For example, in Rebonato's words, the goal of calculating the 99.97 th percentile of a profit/loss distribution with a one-year holding period "is not difficult - it is meaningless". He argues from both a statistical and cognitive point of view, that this combination of percentile and time horizon does not lend itself to be calculated with any confidence or have a useful, meaningful interpretation. Then why is the risk management community spending millions of dollars (per institution) working towards a goal that is not realistically achievable?

Rebonato does his best to review the history of risk management and provide some plausible explanations of how the industry ended up in its current situation. More importantly, the book does present possible solutions to the dilemma. There is no magic; the author proposes that risk managers should focus on questions that can actually be addressed. This process involves a mixture of scenario analysis and the use of the lower percentiles of profit/loss distributions that can be calculated with some confidence. The questions that one should attempt to answer are 'can I survive the worst plausible outcome?', 'how much do I gain in the best plausible outcome?' and 'what is my breakeven?' He also encourages risk managers to use the tools of bayesian analysis, decision theory and even experimental psychology if possible.

Overall I found the book to be an enjoyable read. Many of the ideas put forward agree well with my own opinions and that of some of my colleagues. Rebonato displays some courage in writing a book like this. He questions the very foundations and purposes of risk management. He does not hide behind 'industry best practices', he questions it. In my opinion this book is best suited for industry professionals such as risk managers, regulators and policy makers. Those individuals interested in financial topics will also find the book interesting and entertaining; however, they may not fully appreciate how relevant Rebonato's book is at this time.

As a final note to physicists who are interested in the subject of financial risk management, this book is not intended to provide a rigorous explanation of modern financial risk management techniques. There are other books on the subject that serve this purpose. The true value of this book is Rebonato's questioning of the current practices and goals. He forces us to step back and think about the current situation.

\section{Alexander Marini}

Alexander Marini is Senior Manager, Market Risk and Risk Technology, La Banque Nationale du Canada, 1155 Metcalfe Street Montréal, Quebec, Canada H3B 5G2. He has a PhD in theoretical high-energy physics.

\section{On our bookshelf}

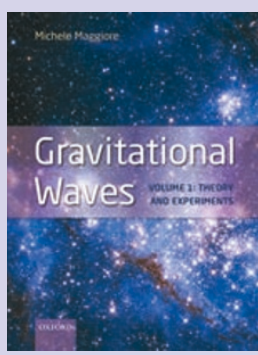

Gravitational Waves: Volume 1 - Theory and Experiments by Michele Maggiore Oxford Univ. Press: 2007. 554 pp. £45

In this first textbook of its kind, the author aims "to bring the reader to the forefront of present-day research, both theoretical and experimental, assuming no previous knowledge of gravitational-wave physics".

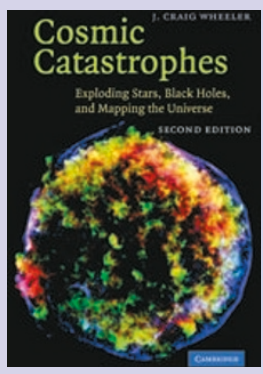

Cosmic Catastrophes: Exploding Stars, Black Holes, and Mapping the Universe by J. Craig Wheeler Cambridge Univ. Press: 2007. 339 pp. £25

From star formation to supernovae to neutron stars and black holes, stellar evolution is anything but mundane. The new edition covers the expanding view of space and time, including wormholes and time machines. 